\title{
The effect of carbohydrate and fat variation in euenergetic diets on postabsorptive free fatty acid release
}

\author{
Peter H. Bisschop ${ }^{1,5}$, Mariëtte T. Ackermans ${ }^{2}$, Erik Endert ${ }^{2}$, An F. C. Ruiter ${ }^{2}$, Alfred J. Meijer ${ }^{3}$, \\ Folkert Kuipers $^{4}$, Hans P. Sauerwein ${ }^{1}$ and Johannes A. Romijn ${ }^{5}$ \\ ${ }^{1}$ Departments of Endocrinology and Metabolism, ${ }^{2}$ Clinical Chemistry and ${ }^{3}$ Biochemistry, Academic Medical Center, \\ University of Amsterdam, PO Box 22700, 1100 DE Amsterdam, The Netherlands \\ ${ }^{4}$ Center for Liver, Digestive and Metabolic Diseases, Academic Hospital Groningen, Hanzeplein 1, 9713 GZ Groningen, \\ The Netherlands \\ ${ }^{5}$ Department of Endocrinology, Leiden University Medical Center, PO Box 9600, 2300 RC Leiden, The Netherlands
}

(Received 16 July 2001 - Revised 15 January 2002 - Accepted 3 February 2002)

\begin{abstract}
Diet composition and energy content modulate free fatty acid (FFA) release. The aim of this study was to evaluate the dose-response effects of euenergetic variations in dietary carbohydrate and fat content on postabsorptive FFA release. The rate of appearance $\left(\mathrm{R}_{\mathrm{a}}\right)$ of palmitate was measured by infusion of $\left[2,2-{ }^{2} \mathrm{H}_{2}\right]$ palmitate after an overnight fast in six healthy men on three separate occasions, i.e. after $7 \mathrm{~d}$ on euenergetic control, high-carbohydrate and high-fat diets. The protein content and composition was identical for each diet. Postabsorptive plasma fatty acid concentrations were not different between the high-carbohydrate and control diets $(0.36$ (SE 0.07) v. 0.43 (SE 0.04) $\mathrm{mmol} / \mathrm{l})$, but were increased after the high-fat diet $(0.75$ (SE $0.09) \mathrm{mmol} / \mathrm{l},(P<0.01$ compared with the other diets $) . \mathrm{R}_{\mathrm{a}}$ palmitate was not different between the high-carbohydrate and control diets (1.36 (SE 0.20) v. 1.47 (SE 0.15) $\mu \mathrm{mol} / \mathrm{kg}$ per min). However, $\mathrm{R}_{\mathrm{a}}$ palmitate was increased to 2.36 (SE 0.26) $\mu \mathrm{mol} / \mathrm{kg}$ per min after the high-fat diet $(P<0 \cdot 01$ compared with the other diets). The fatty acid flux and whole-body fat oxidation were not affected by the high-carbohydrate diet compared with the control diet, but were increased by 67 and $47 \%$ respectively, on the high-fat diet $(P<0 \cdot 01$ compared with the other diets). A euenergetic high-fat diet results in increased postabsorptive FFA release and fat oxidation, whereas a euenergetic high-carbohydrate diet does not affect these variables of fat metabolism.
\end{abstract}

Free fatty acid release: High-fat diet: High-carbohydrate diet: Palmitate

Triacylglycerol stored in adipocytes are the major energy reserve of the body. From these triacylglycerols, fatty acids are continuously released into the blood to provide substrate for oxidation elsewhere in the body. The regulation of free fatty acid (FFA) release is complex and has been extensively studied during starvation. FFA release increases considerably during prolonged starvation (Klein et al. 1986; Klein \& Wolfe, 1992). Both decreased insulin (Klein et al. 1990) and increased adrenaline concentrations (Wolfe et al. 1985; Jensen et al. 1987; Klein et al. 1989) contribute to this acceleration of FFA release. Whether the adaptation of FFA release to starvation is caused by energy deprivation or by mere carbohydrate restriction has been addressed in several studies. Energy deprivation per se did not prove to be a major factor involved in the regulation of FFA release during starvation, since intravenously administered triacylglycerol during a $84 \mathrm{~h}$ oral fast, in amounts that met the daily energy requirements, did not change the adaptation of FFA release to starvation (Klein \& Wolfe, 1992). The increase in FFA release during starvation can neither be explained by mere carbohydrate restriction, because continuous intravenous administration of glucose (about $250 \mathrm{~g} / \mathrm{d}$ ) during oral starvation attenuated the lipolytic response to starvation, but did not completely prevent it (Klein et al. 1990). Apparently, other nutritional components or a combination of components are involved in the regulation of postabsorptive FFA release. In the present study, we evaluated the dose-response relation between dietary carbohydrate and fat content and postabsorptive fatty acid metabolism. Palmitate flux and

Abbreviations: FFA, free fatty acid; Ra, rate of appearance.

* Corresponding author: Dr Peter H. Bisschop, fax +31 20 6917682, email P.H.Bisschop@amc.uva.nl 
whole-body fat oxidation were measured after an overnight fast in six healthy males on three occasions, i.e. after $7 \mathrm{~d}$ on euenergetic control, high-carbohydrate and high-fat diets.

\section{Subjects and methods}

\section{Subjects}

Six healthy men (age $29-55$ years, BMI $21-26 \mathrm{~kg} / \mathrm{m}^{2}$ ) participated in this study. All subjects were in good health and did not use medication. Each participating subject gave written informed consent. This study was approved by the Medical Ethical Committee of the Academic Medical Center, University of Amsterdam.

\section{Diets}

The subjects were studied three times, each time after $7 \mathrm{~d}$ on a different diet. The sequence of the three studies was determined by balanced assignment. The three diets consisted of liquid formulas and contained identical amounts of protein (15\% energy) with identical composition. In addition to the protein, the high-carbohydrate diet provided $85 \%$ total energy as carbohydrate. The control diet provided $44 \%$ total energy as carbohydrate and $41 \%$ as fat. The high-fat diet provided $2 \%$ total energy as carbohydrate and $83 \%$ as fat. The saturated:monounsaturated:polyunsaturated fat ratios were 2:2:1 for all diets containing fat. Energy requirements for each subject were assessed by a dietitian by means of a detailed $3 \mathrm{~d}$ dietary journal. The diets supplied 138 (SE 6). KJ/kg body weight. Meals with predetermined amounts of energy were taken at six fixed time points each day between 08.00 and 21.30 hours for $7 \mathrm{~d}$. In addition to the diets, the subjects were only allowed to drink water ad libitum. Subjects were seen daily to receive their diet for the next day. All subjects refrained from alcohol and exercise was limited to normal daily activities during the experimental diets. For each subject the period between the beginnings of two successive experimental diets was $8-10$ weeks, during which period the subjects consumed their habitual diet.

\section{Protocol}

Subjects were studied after an overnight fast of $16 \mathrm{~h}$. The night before the study a potassium- $\left[2,2{ }^{2} \mathrm{H}_{2}\right]$ palmitate solution was prepared. Potassium- $\left[2,2-{ }^{2} \mathrm{H}_{2}\right]$ palmitate (98\%; Cambridge Isotope Laboratories Inc., Andover, MA, USA) was dissolved in $20 \mathrm{ml}$ sterile water and heated for $2 \mathrm{~h}$ at $55^{\circ} \mathrm{C}$. The potassium- $\left[2,2{ }^{2} \mathrm{H}_{2}\right]$ palmitate was added to human albumin $(200 \mathrm{ml} / \mathrm{l})$ at $55^{\circ} \mathrm{C}$ to achieve a molar ratio of 2.907:1.000 (palmitate:albumin) and the solution was allowed to cool down to room temperature. At 10.00 hours a continuous infusion of potassium$\left[2,2-{ }^{2} \mathrm{H}_{2}\right]$ palmitate bound to human albumin was started, at a rate of $0.05 \mu \mathrm{mol} / \mathrm{kg}$ per min, via a catheter in an antecubital vein. Arterialized blood samples for measurement of palmitate enrichment and FFA and hormone concentrations were taken at 10.00, 11.00, 11.15 and 11.30 hours from a catheter in a contra-lateral antecubital vein. Samples were immediately centrifuged for $10 \mathrm{~min}$ at
$3000 \mathrm{rpm}$ and stored at $-80^{\circ} \mathrm{C}$ until analysis. $\mathrm{O}_{2}$ consumption $\left(V_{\mathrm{O}_{2}}\right)$ and $\mathrm{CO}_{2}$ production $\left(V_{\mathrm{CO}_{2}}\right)$ were measured on an energy expenditure unit (Sensormedics model 2900, Anaheim, CA, USA) with the ventilated hood technique. $\left(V_{\mathrm{O}_{2}}\right)$ and $\left(V_{\mathrm{CO}_{2}}\right)$ were measured continuously between 11.00 and 11.30 hours. The mean rates of $\left(V_{\mathrm{O}_{2}}\right)$ and $\left(V_{\mathrm{CO}_{2}}\right)$ between 11.10 and 11.30 hours were used for calculation of fat oxidation as described by Frayn (1983).

\section{Analytical procedures}

Fatty acids were extracted, isolated and derivatized as described by Ingalls et al. $(1993,1995)$ with some small modifications. To measure concentrations and enrichments in a single chromatographic run, the GC column was split at the end: one piece of deactivated silica tube was directed to a flame ionization detector and another piece of silica tube to a mass selective detector. The flame ionization detector data were used to calculate the concentration of the individual fatty acids and the mass selective detector data were used to calculate palmitate enrichments. To achieve reliable results for the tracer:tracee ratios, calibration curves were constructed as described by Patterson et al. (1998).

Plasma insulin concentration was determined by radioimmunoassay (Insulin RIA 100; Pharmacia Diagnostic $\mathrm{AB}$, Uppsala, Sweden), intra-assay CV 3-5\%, interassay CV 6-9\%, detection limit 15 pmol/l. C-peptide was determined by radioimmunoassay (RIA-coat c-peptide; Byk-Sangtec Diagnostica GmbH \& Co. KG, Dietzenbach, Germany), intra-assay CV 4-6\%, inter-assay CV 6-8\%, detection limit $50 \mathrm{pmol} / \mathrm{l}$. Noradrenaline and adrenaline were determined by an in-house HPLC method (noradrenaline intra-assay CV 6-8\%, inter-assay CV 7-10\%, detection limit $0.05 \mathrm{nmol} / 1$; adrenaline intra-assay $\mathrm{CV} 6-8 \%$, inter-assay CV 7-12\%, detection limit $0.05 \mathrm{nmol} / \mathrm{l}$ ).

\section{Calculations and statistics}

The rate of appearance $\left(\mathrm{R}_{\mathrm{a}}\right)$ of palmitate was calculated using the steady state equation, as adapted for stable isotopes (Rosenblatt \& Wolfe, 1988). R $\mathrm{a}$ FFA was calculated by dividing $\mathrm{R}_{\mathrm{a}}$ palmitate by palmitate:total FFA concentration. All values are given as means with their standard errors. Differences between the three diets were analysed by ANOVA for randomized block design. When appropriate, post hoc comparisons were made by Fisher's least significant difference test. We used SPSS (SPSS Inc., Chicago, IL, USA) for the statistical analysis. Statistical significance was set at $P<0.05$

\section{Results}

The effects of the three diets on postabsorptive glucose and hormone concentrations are shown in Table 1. The dietary carbohydrate and fat content did not affect plasma catecholamine concentrations, whereas the high-fat diet decreased fasting plasma glucose, insulin and C-peptide concentrations.

Plasma fatty acid concentrations were not different between the high-carbohydrate and control diets, but 
Table 1. Plasma substrate and hormone concentrations after $7 \mathrm{~d}$ on a high-carbohydrate, control and high-fat diet $\ddagger$

(Mean values with their standard errors for six healthy men)

\begin{tabular}{|c|c|c|c|c|c|c|}
\hline \multirow[t]{2}{*}{ Diet... } & \multicolumn{2}{|c|}{ High-carbohydrate } & \multicolumn{2}{|c|}{ Control } & \multicolumn{2}{|c|}{ High-fat } \\
\hline & Mean & SE & Mean & SE & Mean & SE \\
\hline Glucose $(\mathrm{mmol} / \mathrm{l})$ & $5 \cdot 1$ & 0.1 & $5 \cdot 1$ & 0.1 & $4 \cdot 3^{\star *}$ & 0.3 \\
\hline Insulin (pmol/l) & 40 & 4 & 36 & 3 & $23+$ & 4 \\
\hline C-peptide (pmol/l) & 525 & 87 & 439 & 49 & $177 \dagger$ & 64 \\
\hline Adrenaline $(\mathrm{nmol} / \mathrm{l})$ & 0.25 & 0.03 & 0.38 & 0.19 & 0.21 & 0.06 \\
\hline Noradrenaline $(\mathrm{nmol} / \mathrm{l})$ & 1.59 & 0.29 & 1.82 & 0.29 & 1.60 & 0.16 \\
\hline
\end{tabular}

Mean values were significantly different from control values: $\dagger P<0.02 ;{ }^{* \star} P<0.01$.

$\ddagger$ For details of subjects, diets and procedures, see p. 556 .

were increased after the high-fat diet $(P<0 \cdot 01$; Fig. 1). In accordance, $\mathrm{R}_{\mathrm{a}}$ palmitate was not different between the high-carbohydrate and control diet (1.36 (SE 0.20) v. 1.47 (SE $0 \cdot 15) \mu \mathrm{mol} / \mathrm{kg}$ per min respectively). On the high-fat diet, $\mathrm{R}_{\mathrm{a}}$ palmitate was increased to 2.36 (SE 0.26) $\mu \mathrm{mol} /$ $\mathrm{kg}$ per min $(P<0.01 v$. the other diets). In line with the changes, in $\mathrm{R}_{\mathrm{a}}$ palmitate, $\mathrm{R}_{\mathrm{a}}$ FFA was not affected by the high-carbohydrate diet compared with the control diet, but was $67 \%$ greater after the high-fat diet $(P<0.01 v$. the other diets) (Fig. 1).

Respiratory quotients were 0.82 (SE 0.03) and 0.78 (SE 0.02 ) on the high-carbohydrate and control diet respectively (NS) and 0.72 (SE 0.03) on the high-fat diet $(P<0.05 v$. the other diets). Whole body-fat oxidation was not different between the high-carbohydrate and control diets, but was increased by $47 \%$ on the high-fat diet $(P<0.01$ v. the other diets) (Fig. 1).

\section{Discussion}

The results from the present study indicate that euenergetic replacement of dietary carbohydrates by fat increases postabsorptive FFA release and fat oxidation, whereas euenergetic fat deprivation does not alter these variables of fat metabolism compared with a control diet.

The diets used in the present study had identical energy contents and provided an identical amount and composition of protein. Therefore, the observed effects can only be attributed to changes in carbohydrate and fat content and not to energy deprivation or protein deficiency. The small sample size used in this study does not cause limitations in making conclusions about observed differences between diets, but an apparent absence of differences should be interpreted with care. The high-fat diet is a ketogenic, which might lead to overestimation of fat oxidation since the respiratory quotient of production and subsequent oxidation of ketones is similar to that of fat oxidation. However, most ketones are produced from fat and their oxidation represents delayed fat oxidation. Thus, it is not likely that oxidation of ketones has lead to significant overestimation of fat oxidation.

Major factors controlling the release of FFA from adipocytes are insulin and catecholamines. In addition to alterations in secretion of these hormones, the sensitivity of adipocytes to the action of hormones involved in the regulation of FFA release may change under certain conditions (Jensen et al. 1987; Klein et al. 1990). In the present study, reduced fasting insulin concentrations after the high-fat diet probably contributed to the increased fatty acid turnover. The dose-response curve of insulin on FFA release has the steepest slope in the low physiological range of insulin concentrations (Jensen et al. 1989). Therefore, a small decrease in insulin concentrations within this range will considerably stimulate FFA release. Moreover, in a previous study we have found that after $11 \mathrm{~d}$ on a high-fat diet, plasma fatty acid concentrations were increased during a hyperinsulinaemic euglycemic clamp as compared with a control diet (Bisschop et al. 2001). Thus, in addition to reduced insulin concentrations, the sensitivity of FFA release to the action of insulin is probably reduced by the high-fat diet. In the present study catecholamine concentrations were not different between the diets as opposed to starvation, which is accompanied by increased adrenaline levels (Klein et al. 1986, 1990; Wolfe et al. 1987). Finally, we cannot exclude the possibility that the slight decrease in plasma glucose concentrations may have contributed to the increased rate of FFA release, but this factor is likely to be quantitatively less important than the changes in insulin secretion and sensitivity (Klein et al. 1986, 1990; Wolfe et al. 1987).

Many of the postabsorptive metabolic changes induced by the high-fat, carbohydrate-restricted diet are comparable with those observed in starvation. This diet decreased glucose and insulin concentrations, whereas it increased FFA release and fat oxidation rates in accordance with previous reports (Whitley et al. 1997). FFA turnover is also increased in starvation. In previous studies. $\mathrm{R}_{\mathrm{a}}$ palmitate ranged from 2.8 to $4.0 \mu \mathrm{mol} / \mathrm{kg}$ per min after $82-84 \mathrm{~h}$ starvation (Klein et al. 1986, 1990; Klein \& Wolfe, 1992). In the present study, $\mathrm{R}_{\mathrm{a}}$ palmitate was $2.4 \mu \mathrm{mol} / \mathrm{kg}$ per min after $7 \mathrm{~d}$ on a carbohydrate-free diet, which is only slightly lower compared with the values mentioned earlier after prolonged starvation. This difference might be related to different adrenaline levels. Adrenaline levels increase during starvation (Wolfe et al. 1985). However, on the high-fat diet postabsorptive adrenaline levels were not different compared with the values obtained on the control diet. Our results extend the observations of Klein \& Wolfe (1992), which were obtained during enteral starvation. Infusion of Intralipid 20\% (Clintec Nutrition, Deerfield, IL, USA) during starvation to meet basal energy requirements did not prevent the increase in plasma adrenaline 

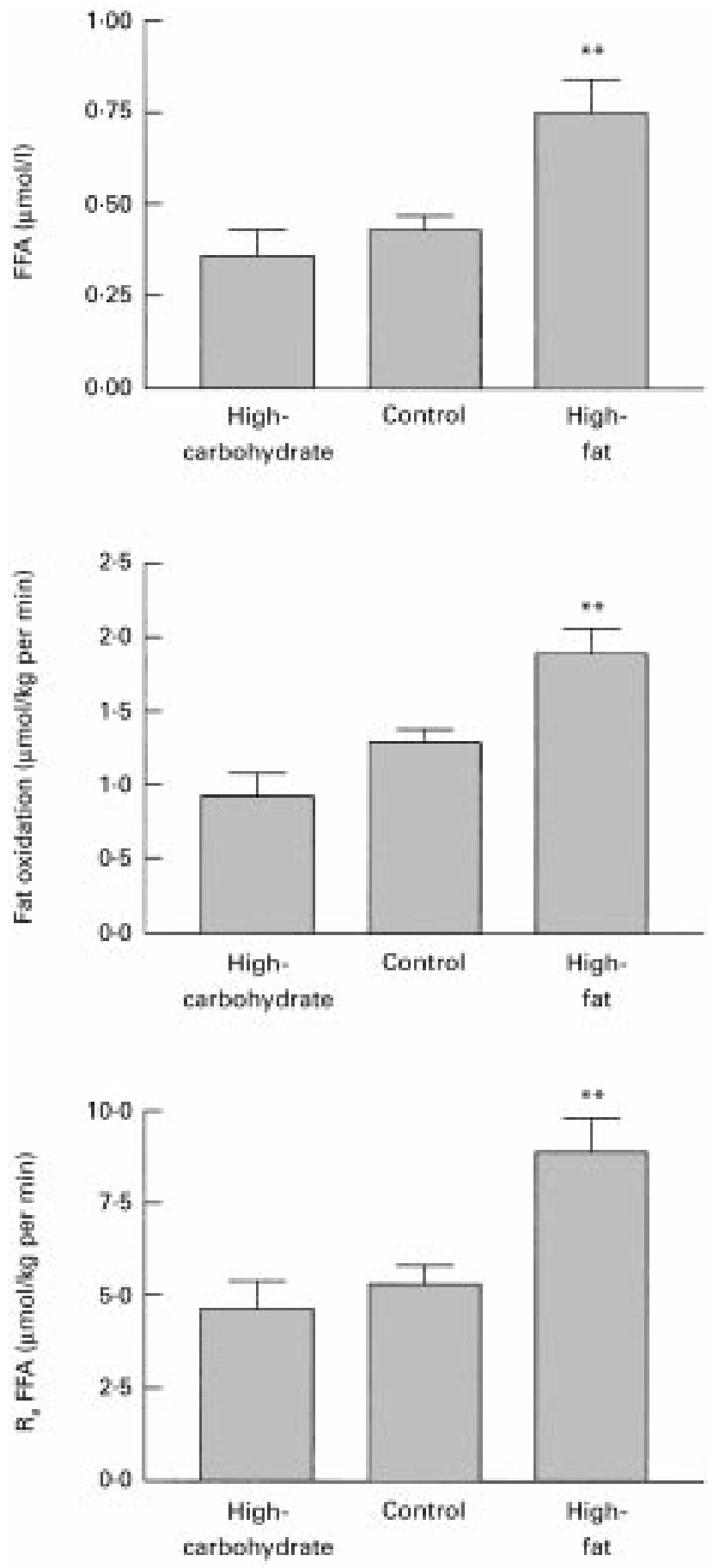

Fig. 1. Effect of high-carbohydrate, control and high-fat diets for $7 d$ on plasma free fatty acid (FFA) concentration, fat oxidation rate and rate of appearance $\left(R_{a}\right)$ of FFA. For details of subjects, diets and procedures, see p. 556. Values are means for six subjects with standard errors shown by vertical bars. Mean values were significantly different from those of the control diet: ${ }^{* *} P<0.01$.

concentrations or in $\mathrm{R}_{\mathrm{a}}$ palmitate observed during complete starvation (Klein \& Wolfe, 1992). Thus, the postabsorptive effects of carbohydrate-restriction in euenergetic diets resemble the effects of prolonged starvation to a large extent.

Several metabolic disorders like hepatic steatosis, insulin resistance and type 2 diabetes mellitus are associated with increased release of FFA into the blood (Nurjhan et al. 1992; Puhakainen et al. 1992; Eriksson et al. 1999). In this respect it is noteworthy that there were no differences in FFA turnover between the fat-free and control diet, which is in accordance with previous observations (Roust et al. 1994). This implys that a high-carbohydrate or low-fat diet has no potentially beneficial effect on postabsorptive fatty acid flux as compared with a normal diet. Conversely, the carbohydrate-free diet might deteriorate insulin resistance, as judged from the induction of hepatic insulin resistance in healthy subjects after a carbohydrate-free diet (Bisschop et al. 2001).

We conclude that a euenergetic high-fat diet results in increased FFA release and fat oxidation, whereas a highcarbohydrate diet does not affect FFA release and fat oxidation. The effects of euenergetic carbohydrate restriction resemble to a large extent the known effects of starvation on fat metabolism.

\section{Acknowledgements}

This study was supported by the Dutch diabetes Research Foundation (grant 96.604).

\section{References}

Bisschop PH, de Metz J, Ackermans MT, Endert E, Pijl H, Kuipers F, Meijer AJ, Sauerwein HP \& Romijn JA (2001) Dietary fat content alters insulin-mediated glucose metabolism in healthy males. American Journal of Clinical Nutrition 73, 554-559.

Eriksson JW, Smith U, Waagstein F, Wysocki M \& Jansson PA (1999) Glucose turnover and adipose tissue lipolysis are insulinresistant in healthy relatives of type 2 diabetes patients: is cellular insulin resistance a secondary phenomenon? Diabetes $\mathbf{4 8}$, $1572-1578$.

Frayn KN (1983) Calculation of substrate oxidation rates in vivo from gaseous exchange. Journal of Applied Physiology: Respiratory Environmental and Exercise Physiology 55, 628-634.

Ingalls ST, Kriaris MS, Xu Y, DeWulf DW, Tserng KY \& Hoppel CL (1993) Method for isolation of non-esterified fatty acids and several other classes of plasma lipids by column chromatography on silica gel. Journal of Chromatography B 619, 9-19.

Ingalls ST, Xu Y \& Hoppel CL (1995) Determination of plasma non-esterified fatty acids and triglyceride fatty acids by gas chromatography of their methyl esters after isolation by column chromatography on silica gel [see comments]. Journal of Chromatography B 666, 1-12.

Jensen MD, Caruso M, Heiling V \& Miles JM (1989) Insulin regulation of lipolysis in nondiabetic and IDDM subjects. Diabetes 38, 1595-1601.

Jensen MD, Haymond MW, Gerich JE, Cryer PE \& Miles JM (1987) Lipolysis during fasting Decreased suppression by insulin and increased stimulation by epinephrine. Journal of Clinical Investigation 79, 207-213.

Klein S, Holland OB \& Wolfe RR (1990) Importance of blood glucose concentration in regulating lipolysis during fasting in humans. American Journal of Physiology 258, E32-E39.

Klein S, Peters EJ, Holland OB \& Wolfe RR (1989) Effect of short- and long-term beta-adrenergic blockade on lipolysis during fasting in humans. American Journal of Physiology 257, E65-E73.

Klein S \& Wolfe RR (1992) Carbohydrate restriction regulates 
the adaptive response to fasting. American Journal of Physiology 262, E631-E636.

Klein S, Young VR, Blackburn GL, Bistrian BR \& Wolfe RR (1986) Palmitate and glycerol kinetics during brief starvation in normal weight young adult and elderly subjects. Journal of Clinical Investigation 78, 928-933.

Nurjhan N, Consoli A \& Gerich J (1992) Increased lipolysis and its consequences on gluconeogenesis in non-insulin-dependent diabetes mellitus. Journal of Clinical Investigation $\mathbf{8 9}$, 169-175.

Patterson BW, Zhao G \& Klein S (1998) Improved accuracy and precision of gas chromatography/mass spectrometry measurements for metabolic tracers. Metabolism: Clinical and Experimental 47, 706-712.

Puhakainen I, Koivisto VA \& Yki-Jarvinen H (1992) Lipolysis and gluconeogenesis from glycerol are increased in patients with noninsulin-dependent diabetes mellitus. Journal of Clinical Endocrinology and Metabolism 75, 789-794.
Rosenblatt J \& Wolfe RR (1998) Calculation of substrate flux using stable isotopes. American Journal of Physiology 254, E526-E531.

Roust LR, Hammel KD \& Jensen MD (1994) Effects of isoenergetic, low-fat diets on energy metabolism in lean and obese women. American Journal of Clinical Nutrition 60 , 470-475.

Whitley HA, Humphreys SM, Samra JS, Campbell IT, MacLaren DP, Reilly T \& Frayn KN (1997) Metabolic responses to isoenergetic meals containing different proportions of carbohydrate and fat. British Journal of Nutrition 78, 15-26.

Wolfe RR, Peters EJ, Klein S, Holland OB, Rosenblatt J \& Gary H Jr (1987) Effect of short-term fasting on lipolytic responsiveness in normal and obese human subjects. American Journal of Physiology 252, E189-E196.

Wolfe RR, Shaw JH \& Durkot MJ (1985) Effect of sepsis on VLDL kinetics: responses in basal state and during glucose infusion. American Journal of Physiology 248, E732-E740. 